\title{
D-dimer plasma level: a reliable marker for venous thromboembolism after elective craniotomy
}

\author{
Clinical article
}

\author{
*Julian Prell, M.D., ${ }^{1}$ Jens Rachinger, M.D., ${ }^{1}$ Robert Smaczny, M.D., ${ }^{1}$ \\ Bettina-Maria Taute, M.D., ${ }^{2}$ Stefan Rampr, M.D., ${ }^{1}$ Joerg Illert, M.D., ${ }^{1}$ \\ Gershom Koman, M.D., ${ }^{1}$ Christian Marquart, M.D., ${ }^{1}$ Alexandra Rachinger, M.D., ${ }^{1}$ \\ Sebastian Simmermacher, M.D., ${ }^{1}$ Alex Alfieri, M.D., ${ }^{1}$ Christian Scheller, M.D., ${ }^{1}$ \\ and Christian Strauss, M.D. ${ }^{1}$
}

Departments of ${ }^{I}$ Neurosurgery and ${ }^{2}$ Angiology, University of Halle, Halle, Germany

Object. The incidence of deep venous thrombosis (DVT) after craniotomy is reported to be as high as $50 \%$. In outpatients, D-dimer levels of more than $0.5 \mathrm{mg} / \mathrm{L}$ indicate venous thromboembolism (VTE, which subsumes DVT and pulmonary embolism [PE]) with a sensitivity of $99.4 \%$ and a specificity of $38.2 \%$. However, D-dimer levels are believed to be unreliable in postoperative patients. The authors undertook the present study to test the hypothesis that D-dimer levels would be systematically raised in a postoperative population and to define a feasible threshold for identification of VTE.

Methods. Doppler ultrasonography of the lower extremity was performed pre- and postoperatively to evaluate for DVT in 101 patients who underwent elective craniotomy. D-dimer levels were assessed preoperatively and on the 3rd, 7th, and 10th days after surgery. Statistical analysis was carried out to define a feasible threshold for D-dimer levels.

Results. D-dimer plasma levels were found to be systematically raised postoperatively, and they differed between patients with and without VTE in a highly significant way. On the 3rd day after surgery, D-dimer levels of more than $2 \mathrm{mg} / \mathrm{L}$ indicated VTE with a sensitivity of $95.3 \%$ and a specificity of $74.1 \%$, allowing for the definition of a feasible threshold. D-dimer levels of more than $4 \mathrm{mg} / \mathrm{L}$ were observed in all patients who had PE during the postoperative period $(n=9)$. Ventilation time and duration of surgery were identified as highly significant risk factors for the development of VTE.

Conclusions. Using a threshold of $2 \mathrm{mg} / \mathrm{L}$, D-dimer levels will indicate VTE with a high degree of sensitivity and specificity in patients who have undergone craniotomy. Pulmonary embolism seems to be indicated by even higher D-dimer levels. Given that the development of D-dimer plasma levels in the postoperative period follows a principle that can be predicted and that deviations from it indicate VTE, this principle might be applicable to other types of surgery.

(http://thejns.org/doi/abs/10.3171/2013.5.JNS13151)

\section{KEY WORDS • D-dimer - venous thromboembolism • deep venous thrombosis •}

$\mathrm{V}$ ENOUS thromboembolism has been designated the most important avoidable cause of mortality following neurosurgical procedures. ${ }^{7,17}$ Venous thromboembolism (VTE) subsumes deep venous thrombosis (DVT) and pulmonary embolism (PE). Even asymptomatic DVT may lead to PE, $, 13,27$ which proves lethal in up to $50 \%$ of affected neurosurgical patients. ${ }^{13,17}$ Up to $7.5 \%$ of patients undergoing craniotomy have symptom-

\footnotetext{
Abbreviations used in this paper: $\mathrm{AUC}=$ area under the curve; $\mathrm{BMI}=$ body mass index; $\mathrm{DVT}=$ deep venous thrombosis; $\mathrm{LMW}=$ low molecular weight; NPV = negative predictive value; $\mathrm{PE}=$ pulmonary embolism; $\mathrm{PPV}=$ positive predictive value ROC $=$ receiver operating characteristic; VTE = venous thromboembolism.

* Drs. Julian Prell and Jens Rachinger contributed equally to this work.
}

atic DVT, $, 1,4,29$ but DVT may be asymptomatically present in up to $50 \% .9,13$

Although low D-dimer plasma levels will rule out VTE with superb sensitivity, ${ }^{2,8,28}$ a high level is not a specific indicator for the presence of VTE. Various other conditions may also lead to high D-dimer levels. ${ }^{18,22,25,28}$ As a result, specificity for evaluation of VTE has been calculated in the range of 30\%-40\% in outpatients. Specificity is compromised even further in postoperative patients. This effect has been demonstrated in several surgical disciplines, including neurosurgery. ${ }^{10,14,19}$

For the present study, we hypothesized that the activa-

This article contains some figures that are displayed in color online but in black-and-white in the print edition. 
tion of blood coagulation by craniotomy would elevate Ddimer plasma levels in a systematic and predictable way in the absence of VTE and that VTE would elevate D-dimer plasma levels beyond this range, implying a threshold with useful values for sensitivity and specificity in postoperative patients.

To our knowledge, this is the first systematic study to evaluate a specific threshold of D-dimer plasma levels for a postoperative patient cohort.

\section{Methods}

\section{Patient Population}

A single-center prospective study was carried out from April 2010 until February 2012, after approval by the university's ethics committee. Undergoing elective surgery for intracranial pathology via craniotomy and availability of pre- and postoperative Doppler ultrasonography served as the two inclusion criteria. The exclusion criteria were gravidity, age less than 18 years, perioperative administration of blood products, abnormal blood coagulation (thrombocytes and/or plasmatic coagulation factors), administration of antiplatelet agents, preoperative C-reactive protein level greater than $5 \mathrm{mg} / \mathrm{L}$, liver disease, and preoperative detection of DVT. One hundred six consecutive patients met the primary inclusion criteria and gave informed consent.

Five patients were excluded from the study because of preoperatively detected asymptomatic DVT $(n=3)$ or abnormal preoperative blood coagulation $(n=2$; essential thrombocythemia in one case and disturbed thrombocyte function in a platelet-function test in another). Of the remaining 101 patients, 59 were female and 42, male. Their mean age $( \pm \mathrm{SD})$ was $54 \pm 15.4$ years (range $18-82$ years). Mean BMI was 26.9, and 10 of the 101 patients were smokers. In $61.4 \%$ of the patients, the surgically treated pathological condition was supratentorial; in $38.6 \%$ it was infratentorial. In $9.9 \%$ of the cases, the patients harbored high-grade gliomas (WHO Grade III or IV), and in 5.9\%, they had low-grade gliomas. Meningiomas were diagnosed in $33.7 \%$ of the 101 patients. Metastasis was seen in $6.9 \%$ and vestibular schwannoma in $29.7 \%$. In 5 cases, the patients underwent craniotomy for clip ligation of an incidentally found aneurysm. The remaining patients had cavernomas $(n=2)$, neurocytomas $(n=2)$, a hemangioblastoma $(n=1)$, a dermoid cyst $(n=1)$, non-Hodgkin lymphoma $(n=1)$, and trigeminal neuralgia $(n=1)$. Table 1 summarizes the clinical variables.

All patients were treated with compression stockings from surgical positioning until the 5th postoperative day and received subcutaneously administered LMW-heparin (Certoparin, $3000 \mathrm{IU}$, once daily) from the 1st postoperative day until discharge. When VTE was diagnosed, therapeutic anticoagulation therapy was instituted, with administration of LMW-heparin twice a day, the dosage depending on the patient's weight and the surgeon's preference.

\section{Doppler Ultrasonography and Diagnosis of PE}

All examinations were conducted with the same device (Sonoline Antares, Siemens Sector Healthcare) by
TABLE 1: Clinical parameters of the VTE+ and VTE- subgroups ${ }^{*}$

\begin{tabular}{|c|c|c|c|}
\hline Variable & VTE+ & VTE- & $p$ Value \\
\hline no. of patients & 43 & 58 & \\
\hline mean age in yrs & $55.8 \pm 15.1$ & $52.8 \pm 15.7$ & 0.327 \\
\hline \multicolumn{4}{|l|}{ sex } \\
\hline male & 16 & 26 & \\
\hline female & 27 & 32 & \\
\hline$\%$ female & 62.8 & 55.2 & 0.442 \\
\hline \multicolumn{4}{|l|}{ LOS in days } \\
\hline median & 15.8 & 14.1 & 0.084 \\
\hline range & $9-28$ & $8-36$ & \\
\hline mean BMI & $27.2 \pm 4.8$ & $26.7 \pm 4.0$ & 0.537 \\
\hline tobacco smoking & $4(9.3)$ & $6(10.34)$ & $>0.99 \dagger$ \\
\hline preop KPS score & & & - \\
\hline mode & 90 & 90 & \\
\hline range & $80-100$ & $50-100$ & \\
\hline postop KPS score & & & - \\
\hline mode & 80 & 90 & \\
\hline range & $60-100$ & $50-100$ & \\
\hline trepanation in $\mathrm{cm}^{2}$ & & & 0.170 \\
\hline median & 26.3 & 22.2 & \\
\hline range & $4-63$ & $4-114$ & \\
\hline mean duration of op in min & $363 \pm 114$ & $255 \pm 114$ & $<0.001$ \\
\hline mean ventilation time in $\min$ & $473 \pm 115$ & $359 \pm 114$ & $<0.001$ \\
\hline postop bleeding & $2 / 43(4.7)$ & $0 / 58(0)$ & $0.179 \dagger$ \\
\hline WHO Gradef & & & $0.539 \dagger$ \\
\hline | or || & $31 / 69$ & $38 / 69$ & \\
\hline III or IV & $4 / 12$ & $8 / 12$ & \\
\hline \multicolumn{4}{|l|}{ histopathology } \\
\hline meningioma & $16 / 43$ & $18 / 58$ & $>0.99 \dagger$ \\
\hline schwannoma & $14 / 43$ & $16 / 58$ & $0.662 \dagger$ \\
\hline glioma, WHO Grade III or IV & $4 / 43$ & $6 / 58$ & $>0.99 \dagger$ \\
\hline glioma, WHO Grade I or II & $1 / 43$ & $5 / 58$ & $0.236 \dagger$ \\
\hline metastasis & $3 / 43$ & $4 / 58$ & $>0.99 \dagger$ \\
\hline other & $5 / 43$ & $9 / 58$ & $0.772 \dagger$ \\
\hline \multicolumn{4}{|l|}{ location of trepanation } \\
\hline bifrontal & $2 / 43$ & $1 / 58$ & $0.573 \dagger$ \\
\hline frontal & $9 / 43$ & $9 / 58$ & $0.607 \dagger$ \\
\hline frontolateral/pterional & $8 / 43$ & $7 / 58$ & $0.405 \dagger$ \\
\hline occipital/parietal & $1 / 43$ & $9 / 58$ & $0.041 \dagger$ \\
\hline temporal & $5 / 43$ & $6 / 58$ & $>0.99 \dagger$ \\
\hline suboccipital & $3 / 43$ & $10 / 58$ & $0.147 \dagger$ \\
\hline retrosigmoidal & $15 / 43$ & $16 / 58$ & $0.514 \dagger$ \\
\hline supratentorial localization & $29 / 43(67.4)$ & $33 / 58(56.9)$ & 0.282 \\
\hline preop D-dimer level >0.5 mg/L & $17 / 43(39.5)$ & $20 / 58(34.5)$ & 0.602 \\
\hline
\end{tabular}

* Values represent numbers of patients (\%) unless otherwise indicated. Means are given with SDs; $p$-values are 2-tailed, without correction; the highly significant values (in bold type) remain highly significant ( $p$ $<0.001$ ) after Bonferroni correction for multiple comparisons. KPS = Karnofsky Performance Status; LOS = length of hospital stay.

† Fisher exact test.

$\neq$ The denominators in the WHO grade subcategories indicate the total number of patients with tumors of the specified grade; 69 patients had WHO Grade I or II tumors and 12 had WHO Grade III or IV tumors. 
the same examiner (author B.M.T., certified at Level 3 for vascular ultrasound by the German Society for Ultrasound in Medicine [DEGUM, www.degum.de]), who was blinded to D-dimer levels.

Examinations took place on the day before surgery and between the 3rd and 6th days after surgery. Diagnosis of DVT was based on direct thrombus detection by incomplete compressibility of the vessel, observation of lack of blood flow, or both. All anatomical levels of the lowerextremity venous system were thoroughly examined on both sides, including veins of the pelvis (a-sounds). Diagnosed DVTs were subdivided according to consensus terminology ${ }^{3}$ into 2 subtypes: 1) proximal DVT, occurring at the level of or craniad to the trifurcation of the popliteal vein, and 2) distal DVT, occurring distal to this level in the deep veins of the lower leg or in muscle veins within the triceps surae.

These subtypes differ significantly regarding incidence and associated risk of PE..$^{11,24}$ Cases of DVT were also classified into symptomatic and asymptomatic subgroups (criteria: tenderness on palpation, swelling, pain).

Pulmonary embolism was diagnosed by CT examination, which was performed if patients had acute dyspnea, unexplained loss of consciousness, thoracic pain, acutely reduced oxygen saturation, resting tachycardia $(>100$ bpm), or acutely reduced blood pressure.

\section{D-Dimer Plasma Levels}

D-dimer plasma levels were assessed preoperatively and on the 3rd, 7th, and 10th days after surgery with the Siemens Innovance D-dimer test. ${ }^{5,8}$ In an outpatient cohort, sensitivity for this test has been calculated at $99.4 \%$ and specificity at $38.2 \%$ for a threshold of $0.5 \mathrm{mg} / \mathrm{L} .{ }^{8}$

\section{Statistical Analysis}

Statistical analysis was done with IBM SPSS Statistics 19 . The mean values of $\mathrm{D}$-dimer plasma levels before surgery and on the 3rd, 7th, and 10th postoperative days were calculated for patients with and without VTE (VTE+ group vs VTE- group). After logarithmic transformation of these values, between-groups comparisons were performed using the Mann-Whitney U-test and Student t-test. For evaluation of discrimination points, an ROC analysis was conducted.

For evaluation of risk factors for VTE, data pertaining to nondichotomous variables were compared by parametric tests only when a gaussian distribution was confirmed (P-P plots, histograms, Kolmogorov-Smirnov test); otherwise, nonparametric testing was used. For dichotomous variables, the Fisher exact test was used.

Results were deemed significant with $\mathrm{p}<0.05$ and highly significant with $\mathrm{p}<0.001$ (based on 2-tailed tests). The Bonferroni method was used to correct for multiple comparisons.

\section{Results}

Postoperative VTE was diagnosed in $42.6 \%$ of all patients. Deep venous thrombosis was seen in $39.6 \%$ (isolated distal DVT in 25.7\%; proximal DVT, which was always combined with distal DVT, in 13.9\%). Of 40 diagnosed cases of DVT, 9 were symptomatic (representing $22.5 \%$ of the patients with DVT, $8.9 \%$ of all patients). Symptomatic PE was detected in $8.9 \%$ of the patients.

\section{Risk Factors for VTE}

Various clinical variables were assessed and analyzed for their potential impact regarding incidence of VTE (Table 1). A highly significant difference $(\mathrm{p}<0.001)$ was demonstrated exclusively for duration of surgery and for ventilation time. In patients without VTE, the mean duration of surgery was 255 minutes, whereas it was 363 minutes in patients with VTE. The mean ventilation time was 359 minutes in patients without VTE and 473 minutes in patients with VTE. After Bonferroni correction, significance with $\mathrm{p}<0.001$ was retained for both variables.

Trepanation in the occipitoparietal region seemed to be associated with a reduced risk for VTE $(p=0.041)$. However, statistical significance was not retained after Bonferroni correction. Also, patients undergoing this kind of trepanation were observed to have a shorter mean duration of surgery (171 minutes vs 363 minutes).

Postoperative bleeding necessitating surgical evacuation was seen in 2 patients (2\%). Both were in the VTE+ group. In one case, bleeding took place before the first administration of prophylactic LMW-heparin; in the other patient, the bleeding was observed under therapeutic anticoagulation. There was no statistically significant difference between the VTE+ and VTE- groups with respect to incidence of postoperative bleeding.

\section{D-Dimer Plasma Level: Comparison of Mean Values}

Regarding D-dimer plasma level values, the Kolmogorov-Smirnov test excluded a gaussian distribution of the data (KS-Z 1.598, $\mathrm{p}=0.012$ ). Consequently, the data were logarithmically transformed for parametric testing in addition to nonparametric testing (KS-Z after transformation 0.541, $\mathrm{p}=0.931$ ).

Comparison of mean D-dimer plasma levels in the VTE- group and VTE+ group was performed for values obtained preoperatively and on the $3 \mathrm{rd}$, 7th, and 10th postoperative days. Highly significant differences were observed on the 3rd, 7th, and 10th postoperative days ( $\mathrm{p}$ $<0.001$ each), but not preoperatively $(\mathrm{p}=0.195)$ (Fig. 1). Likewise, the nonparametric Mann-Whitney U-test showed highly significant between-groups differences $(p$ $<0.001$ ) for all postoperative measurements, but no significant difference $(\mathrm{p}=0.531)$ in the preoperative mean values (Table 2).

Preoperatively, the mean D-dimer plasma level was $0.62 \mathrm{mg} / \mathrm{L}$ in the patients who did not develop VTE (VTE- group) and $0.74 \mathrm{mg} / \mathrm{L}$ in those who did (VTE+ group). On the 3rd day after surgery it was $1.59 \mathrm{mg} / \mathrm{L}$ in the VTE- group and $5.49 \mathrm{mg} / \mathrm{L}$ in the VTE+ group. This difference decreased over time; on the 7th day, the D-dimer plasma level was $1.29 \mathrm{mg} / \mathrm{L}$ in the VTE- group and $3.8 \mathrm{mg} / \mathrm{L}$ in the VTE+ group, and on the 10th day it was $1.11 \mathrm{mg} / \mathrm{L}$ in the VTE- group and $2.26 \mathrm{mg} / \mathrm{L}$ in the VTE+ group (Fig. 1).

In patients in the VTE- group, D-dimer plasma levels were found to be in a homogeneous range, with stable 


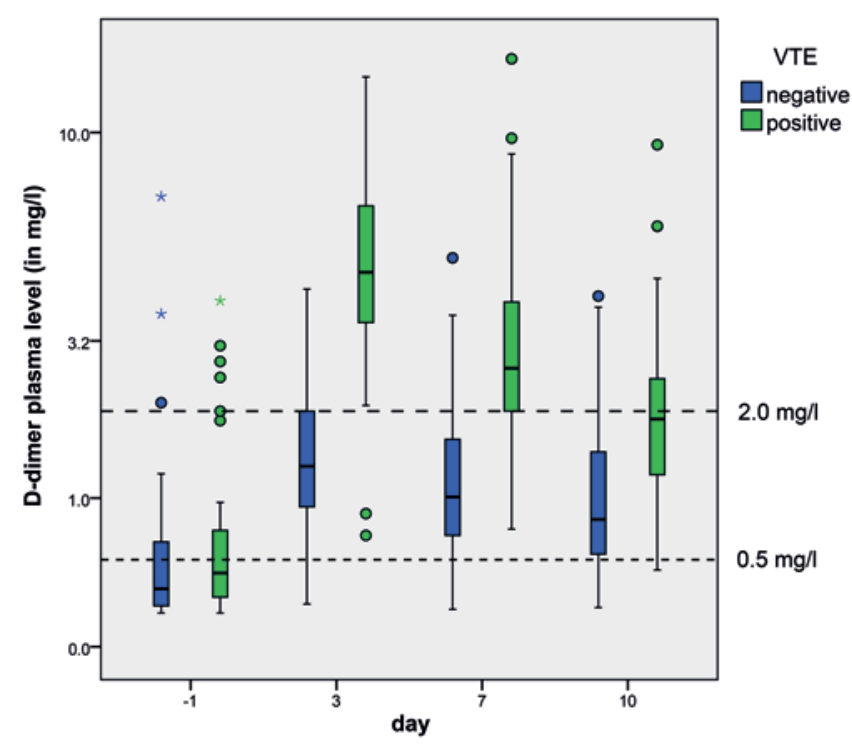

Fig. 1. Boxplot of D-dimer plasma levels over time. The y coordinates indicate D-dimer plasma levels (logarithmic scale). The $x$ coordinates indicate days, with -1 being preoperative, and 3, 7, and 10 indicating the $3 \mathrm{rd}, 7 \mathrm{th}$, and 10 th days after surgery. The boxes include $50 \%$ of the values, with the height representing the interquartile range (IQR); the horizontal bar within the box represents the median; the whiskers extend to $1.5 \times \mathrm{IQR}$; the colored circles represent mild outliers (range $1.5 \times I Q R$ to $3 \times I Q R$ ); and the asterisks represent extreme outliers (> $3 \times I Q R)$. The threshold provided by the test manufacturer $(0.5 \mathrm{mg} / \mathrm{L})$ is shown as well as the proposed threshold chosen for its clinical applicability $(2 \mathrm{mg} / \mathrm{L})$

standard deviations, over the whole time course. An initial rise of the mean value from $0.62 \mathrm{mg} / \mathrm{L}$ preoperatively to $1.59 \mathrm{mg} / \mathrm{L}$ on the $3 \mathrm{rd}$ postoperative day was observed, followed by decline to $1.29 \mathrm{mg} / \mathrm{L}$ on the 7 th day and 1.11 $\mathrm{mg} / \mathrm{L}$ on the 10th day (Fig. 1 and Table 2).

\section{Determination of Discrimination Points: D-Dimer Plasma Level Thresholds}

Discrimination points were evaluated for D-dimer plasma levels only on the 3rd postoperative day, as the levels on the 7th and 10th days were assessed under condi- tions of therapeutic anticoagulation in patients with VTE. This was unavoidable for ethical reasons.

An ROC analysis was used to evaluate D-dimer plasma levels on the 3rd day after surgery with regard to the presence or absence of VTE. The AUC was calculated to be 0.92 with $p<0.001$, a standard error of 0.03 , an asymptotic confidence interval (95\%) ranging from 0.861 to 0.979 . The ROC curve rose vertically, with $100 \%$ specificity, and started to deviate toward lower specificity only after 55\% sensitivity was reached (Fig. 2).

In addition to the standard cut-off value $(0.5 \mathrm{mg} / \mathrm{L}), 4$ additional cut-off values were evaluated. Their characteristics were as follows: 1) optimum sensitivity for VTE, 2) optimum specificity for VTE, 3) optimum balanced sensitivity/specificity (Youden index ${ }^{30}$ ), 4) suggestion for optimum clinical applicability, and 5) standard cut-off value of the Siemens Innovance test $(0.5 \mathrm{mg} / \mathrm{L})$.

For optimum sensitivity (100\%), a cut-off value of $0.86 \mathrm{mg} / \mathrm{L}$ was identified, providing $20.7 \%$ specificity for VTE with an NPV of $100 \%$ and a PPV of $48.3 \%$ (Fig. 2).

A threshold of $4.3 \mathrm{mg} / \mathrm{L}$ provided optimum specificity $(100 \%)$ for VTE with a sensitivity of $55.8 \%$, an NPV of $75 \%$, and a PPV of $100 \%$ (Fig. 2).

The Youden index $(\mathrm{J})$ reaches its maximum value for the specific discrimination point in the ROC curve with maximum distance to the diagonal reference line and optimizes the discriminatory power of a test, assuming that sensitivity and specificity are of the same value. Thus, a cut-off value of $3.3 \mathrm{mg} / \mathrm{L}$ was calculated $(\mathrm{J}=0.72)$. The sensitivity was $79.1 \%$ and the specificity $93.1 \%$. The NPV was $85.7 \%$ and the PPV $89.5 \%$ (Fig. 2).

Based on the data, a specific cut-off value excluding almost all of the patients in the VTE+ group (with the exception of 2 outliers) was defined to provide a threshold emphasizing clinical applicability (Fig. 1). The threshold was rounded and set to $2 \mathrm{mg} / \mathrm{L}$. With this threshold, the sensitivity for VTE was $95.3 \%$ and the specificity was 74.1\%; the NPV was $95.6 \%$, and the PPV $73.2 \%$. In one of the 2 excluded outliers, isolated distal DVT was seen (D-dimer plasma level $0.91 \mathrm{mg} / \mathrm{L}$ on the $3 \mathrm{rd}$ day), and in the other patient we diagnosed combined proximal/distal DVT with a D-dimer level of $0.86 \mathrm{mg} / \mathrm{L}$ (Figs. 1 and 2).

TABLE 2: D-dimer plasma level (in $\mathrm{mg} / \mathrm{L}$ ) and VTE*

\begin{tabular}{rccccccc}
\hline Day & VTE & Mean & SD & $p$ Value $\dagger$ & MD & $95 \% \mathrm{Cl}$ & $p$ Value for Log Dataf \\
\hline-1 & + & 0.74 & 0.87 & 0.531 & 0.12 & -0.26 to 0.51 & 0.195 \\
-1 & - & 0.62 & 1.04 & & & & \\
3 & + & 5.49 & 3.16 & $<0.001$ & 3.89 & $3.02-4.77$ & $<0.001$ \\
3 & - & 1.59 & 0.98 & & & & $<0.001$ \\
7 & + & 3.80 & 3.21 & $<0.001$ & 2.51 & $1.62-3.39$ & $<0.001$ \\
7 & - & 1.29 & 0.94 & & & & \\
10 & + & 2.26 & 1.73 & $<0.001$ & 1.16 & $0.27-0.62$ & \\
10 & - & 1.11 & 0.85 & & & & \\
\hline
\end{tabular}

\footnotetext{
* Evaluation of significance after logarithmic transformation and evaluation of the raw data produced similar results. The results are given here with the raw data because of easier interpretation regarding mean, SD, and MD. For all postoperative comparisons, corrected 2-sided $\mathrm{p}$-values are reported. $\mathrm{Cl}=$ asymptotic confidence interval; $\mathrm{MD}=$ mean difference.

$\dagger$ Mann-Whitney U-test.

$\ddagger$ Student t-test.
} 


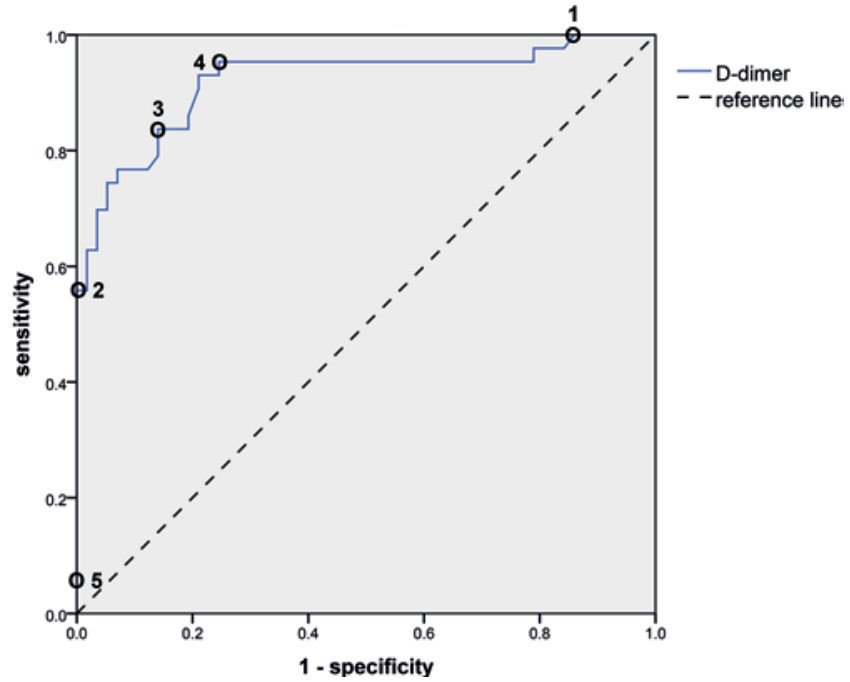

FIG. 2. The ROC curve for D-dimer plasma levels on the 3rd day after surgery with VTE (present vs absent) as the variable and assumption of nonparametric data distribution. The 5 evaluated cut-off values are marked in the diagram: 1 = optimum sensitivity $(0.86 \mathrm{mg} / \mathrm{L}) ; 2=$ optimum specificity $(4.3 \mathrm{mg} / \mathrm{L}) ; 3=$ balanced sensitivity/specificity $(3.3$ $\mathrm{mg} / \mathrm{L}) ; 4$ = proposed cut-off value $(2 \mathrm{mg} / \mathrm{L}) ; 5=$ standard cut-off as provided by test manufacturer $(0.5 \mathrm{mg} / \mathrm{L})$.

With the standard values applied $(0.5 \mathrm{mg} / \mathrm{L})$, the sensitivity was found to be $100 \%$; the specificity, however, was very low, $6.9 \%$. The NPV was $100 \%$, but the PPV was only $44.3 \%$ (Fig. 2).

\section{VTE Subtype and D-Dimer Plasma Levels}

More extensive VTE was associated with higher Ddimer plasma levels (Fig. 3). For patients without VTE, the mean D-dimer plasma level on the 3rd day after surgery was $1.59 \mathrm{mg} / \mathrm{L}$ (range $0.17-4.3 \mathrm{mg} / \mathrm{L}, \mathrm{SD} 0.98 \mathrm{mg} / \mathrm{L}$ ). Patients with isolated distal DVT had a mean of 4.56 $\mathrm{mg} / \mathrm{L}$ (range 0.92-10.21 mg/L, SD $2.12 \mathrm{mg} / \mathrm{L}$ ). In patients with combined proximal and distal DVT, the mean value was $6.36 \mathrm{mg} / \mathrm{L}$ (range $0.86-12.41 \mathrm{mg} / \mathrm{L}, \mathrm{SD} 4.14 \mathrm{mg} / \mathrm{L}$ ). In patients with symptomatic $\mathrm{PE}(\mathrm{n}=9)$, the highest mean D-dimer plasma level was observed: $7.14 \mathrm{mg} / \mathrm{L}$ (range 4.11-13.33 mg/L, SD $3.56 \mathrm{mg} / \mathrm{L}$ ) (Table 3). On the 3rd postoperative day, D-dimer plasma levels differed in a statistically significant way between patients with diagnosed $\mathrm{PE}$ on one side of the spectrum and patients with isolated distal DVT on the other side ( $\mathrm{p}=0.045$ after Bonferroni correction for multiple testing) (Table 4).

\section{Discussion}

The data from this study support the hypothesis that undergoing elective craniotomy raises D-dimer plasma levels in a predictable way, while VTE leads to significantly higher values. Postoperative D-dimer plasma levels were almost universally elevated beyond the standard threshold of $0.5 \mathrm{mg} / \mathrm{L},{ }^{8}$ slowly declining over time during the postoperative period. In patients with VTE, the levels were found to be significantly higher than in those without VTE $(\mathrm{p}<0.001)$.

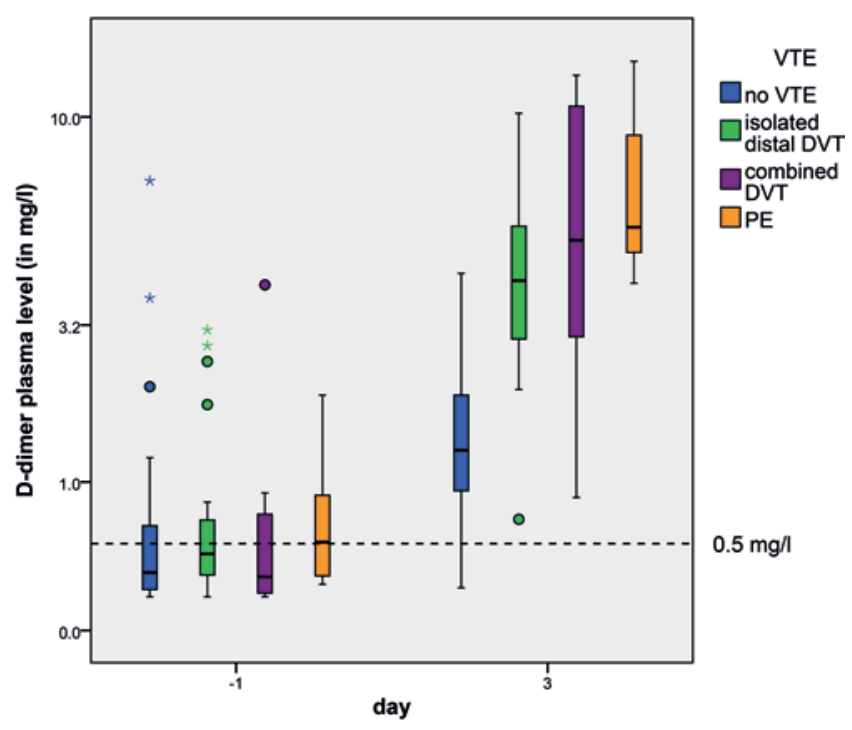

FIG. 3. Boxplot of D-dimer plasma levels stratified by VTE subtypes. The y coordinates indicate D-dimer plasma levels (logarithmic scale). The $x$ coordinates indicate days, with -1 being preoperative and 3 indicating the 3 rd day after surgery. The boxes include $50 \%$ of the values, with the height representing the interquartile range (IQR); the horizontal bar within the box represents the median; the whiskers extend to $1.5 \times$ IQR; the colored circles represent mild outliers (range $1.5 \times$ IQR to $3 \times$ $I Q R)$; and the asterisks represent extreme outliers $(>3 \times I Q R)$.

The development of VTE was not influenced by patient age, Karnofsky Performance Status score, sex, status as a smoker or nonsmoker, the specific pathological condition present and its localization, the extent of the trepanation, raised preoperative D-dimer levels, or BMI. This finding partially contradicts other studies,${ }^{15}$ which have demonstrated a higher risk for VTE in patients with malignancy and older age; the contradiction may be due to the sample size of 101 patients in the present study. However, longer duration of surgery and longer ventilation time proved to be risk factors for the development of VTE in concordance with other studies. ${ }^{17}$

In outpatients, D-dimer testing is usually employed only when clinical signs of VTE are present, but prevalence of DVT even in suspected cases has been reported to be only $19.8 \%$ in meta-analysis. ${ }^{26}$ Circumstances are, however, quite different in a postoperative cohort with a high incidence of newly acquired DVT $(42.6 \%)$ as presented in our study. This is especially true since DVT is believed to be the source of $90 \%$ of all PEs, ${ }^{7}$ and embo-

TABLE 3: D-dimer plasma levels by VTE subtype*

\begin{tabular}{cccccc}
\hline & \multicolumn{5}{c}{ D-Dimer Level (mg/L) } \\
\cline { 2 - 6 } VTE Subtype & Mean & SD & Median & Min & Max \\
\hline 0 & 1.59 & 0.98 & 1.32 & 0.17 & 4.30 \\
1 & 4.56 & 2.12 & 4.12 & 0.92 & 10.21 \\
2 & 6.36 & 4.14 & 5.23 & 0.86 & 12.41 \\
3 & 7.14 & 3.56 & 5.58 & 4.11 & 13.33 \\
\hline
\end{tabular}

* VTE subtypes: 0 = no VTE; 1 = isolated distal DVT; 2 = combined proximal and distal DVT; $3=\mathrm{PE}$. 
TABLE 4: Comparison of VTE subtypes*

\begin{tabular}{cccc}
\hline Comparison & p Value $\dagger$ & $\mathrm{MD}$ & \multicolumn{1}{c}{$95 \% \mathrm{Cl}$} \\
\hline 1 vs 2 & 0.219 & -1.80 & -4.84 to 1.24 \\
2 vs 3 & 0.668 & -0.78 & -4.54 to 2.98 \\
1 vs 3 & 0.015 & -2.58 & -4.62 to -0.53 \\
\hline
\end{tabular}

* See Table 3 for definitions of subtypes.

† All p-values shown are uncorrected and 2-tailed. After Bonferroni correction for multiple comparisons, $p$ remains significant $(p=0.045)$ for the comparison 1 vs 3 . The bolded value is highly significant.

lism proves lethal in up to $50 \%$ of cases. ${ }^{13,17}$ Pulmonary embolism has been observed in $3.7 \%$ of all patients undergoing neurosurgery in a prospective series. ${ }^{15}$ In the present study, symptomatic PE was diagnosed even in $8.9 \%$ of all patients. The routine use of serial sonography for all postoperative patients warrants consideration. Failing this, there is a need for an effective screening method, as shown by the above numbers.

A highly significant deviation from the ROC null hypothesis was found in evaluation of D-dimer plasma levels as a marker for the presence/absence of postoperative VTE. The AUC for our overall group on the 3rd day after surgery was 0.92; this is comparable to findings in outpatients (AUC 0.9). ${ }^{8}$ Thus, the definition of a clinically applicable threshold becomes a conceivable goal.

Based on our data, we propose D-dimer screening with a threshold of $2 \mathrm{mg} / \mathrm{L}$. With this cut-off value, which included all cases other than the 2 statistical outliers (Fig. 1), sensitivity is somewhat lower (95.3\% vs $99.4 \%)$, while specificity is clearly higher $(74.1 \%$ vs $38.2 \%)$ than is achieved when the standard value of $0.5 \mathrm{mg} / \mathrm{L}$ is applied to outpatients. The value of $2 \mathrm{mg} / \mathrm{L}$ appears to be a robust threshold; the great majority of patients with diagnosed VTE presented with D-dimer plasma levels greater than 3 $\mathrm{mg} / \mathrm{L}$ on the 3rd postoperative day (Fig. 1). This value has the potential to be a reliable cut-off value for postoperative screening in neurosurgical patients. In only 1 of 4 patients would the thus-induced additional diagnostic evaluations yield negative results (PPV 73.2\%).

In $95.6 \%$ (NPV) of all patients with D-dimer plasma levels lower than $2 \mathrm{mg} / \mathrm{L}$, no VTE was present on the $3 \mathrm{rd}$ day after surgery, implying that 1 of 20 patients would be at risk for undiagnosed VTE. While not perfect, this test appears to be significantly better than clinical suspicion as the sole "screening" method. In our study group, $8.9 \%$ of all patients presented with clinically apparent DVT. This percentage is comparatively high but is still within the same general magnitude as values found in the literature for patients harboring intracranial tumors $(2.3 \%-7.5 \%) ; 4,29$ the relatively high percentage might be partially explained by the raised vigilance for DVT as the prospective study was conducted. However, the general incidence of DVT (39.6\%) was more than 4 times higher than the incidence of symptomatic DVT (8.9\%). Given these proportions, more than 3 of 4 patients with DVT would remain undiagnosed and at risk without D-dimer screening.

The high incidence of VTE found in the present study stresses the perception of the neurosurgical patient as a high-risk patient with respect to this condition. As a consequence, the prevention of VTE deserves more attention. Intermittent pneumatic compression might be of value. Given that ventilation time and duration of surgery were the only identifiable risk factors for postoperative VTE with $\mathrm{p}<0.001$ each, it appears that DVT develops during surgery itself in the majority of patients. Consequently, intermittent pneumatic compression may be most efficient when started intraoperatively.

The majority of patients with VTE in the present study harbored (mostly asymptomatic) distal DVT. The 9th edition of the American College of Chest Physicians (ACCP) guidelines on antithrombotic therapy and prevention (http://journal.publications.chestnet.org/issue.aspx? journalid=99\&issueid $=23443 \&$ direction $=P$ ) recommends follow-up ultrasonography in patients with isolated distal DVT or initial treatment with anticoagulant agents if risk factors are present. According to the guidelines, active cancer and hospitalized status are believed to be among these risk factors. The recommendations are based primarily on natural history studies, which show that distal DVT may progress and affect more proximal venous structures in up to $15 \%$ of cases and that this is most likely to occur during the first 2 weeks after surgery. ${ }^{16,20,21,23}$

The incidence of symptomatic PE due to DVT in muscle veins was reported to be $7 \%$, and the rate of recanalization in patients treated with therapeutic anticoagulation has been given as $85 \% .{ }^{12}$ Given all these observations and recommendations, many centers will treat distal DVT despite its comparatively low risk of complications, as the fear of the complications associated with DVT outweighs the fear of complications associated with anticoagulation. With respect to the data presented, it seems that therapeutic anticoagulation is surprisingly safe even in a high-risk population of patients who have very recently undergone brain surgery. Two instances of postoperative bleeding were observed. Although both patients were in the VTE+ group, the bleeding was potentially associated with therapeutic anticoagulation in only one of them (in the other patient, the bleeding took place even before administration of the first prophylactic LMW-heparin dose).

\section{Conclusions}

Using a threshold of $2 \mathrm{mg} / \mathrm{L}$, D-dimer levels will indicate VTE in patients after craniotomy with high sensitivity and specificity. Pulmonary embolism seems to be indicated by even higher D-dimer levels. Ventilation time and duration of surgery are highly significant risk factors for the development of VTE; other clinical factors, such as tumor entity and the extent of operative trauma, do not seem to play a key role in this respect.

The present study was conducted in a strictly neurosurgical patient group after elective craniotomy. We are, however, convinced that our results are, in principle, transferable to any reasonably homogeneous postoperative patient population. Future studies are needed to determine the respective D-dimer threshold for these patient groups.

\section{Disclosure}

Funding for this study was provided by the Wilhelm Roux Pro- 
gram of the Martin Luther University Halle-Wittenberg, Germany (FKZ 21/33).

Author contributions to the study and manuscript preparation include the following. Conception and design: Prell, J Rachinger, Strauss. Acquisition of data: Smaczny, Taute, Illert, Koman, Marquart, A Rachinger, Simmermacher, Alfieri, Scheller. Analysis and interpretation of data: Prell, J Rachinger, Smaczny, Taute, Rampp. Drafting the article: Prell, Strauss. Critically revising the article: J Rachinger, Smaczny, Taute, Rampp, Illert, Koman, Marquart, A Rachinger, Simmermacher, Alfieri, Scheller, Strauss. Reviewed submitted version of manuscript: J Rachinger, Smaczny, Taute, Rampp, Illert, Koman, Marquart, A Rachinger, Simmermacher, Alfieri, Scheller, Strauss. Approved the final version of the manuscript on behalf of all authors: Prell. Statistical analysis: Smaczny, Rampp. Administrative/technical/material support: Taute, Illert, Koman, Marquart, A Rachinger, Alfieri, Scheller, Strauss. Study supervision: J Rachinger, Strauss.

\section{References}

1. Agnelli G, Piovella F, Buoncristiani P, Severi P, Pini M, D'Angelo A, et al: Enoxaparin plus compression stockings compared with compression stockings alone in the prevention of venous thromboembolism after elective neurosurgery. $\mathbf{N}$ Engl J Med 339:80-85, 1998

2. Bounameaux H, Perrier A, Righini M: Diagnosis of venous thromboembolism: an update. Vasc Med 15:399-406, 2010

3. Caggiati A, Bergan JJ, Gloviczki P, Eklof B, Allegra C, Partsch $\mathrm{H}$ : Nomenclature of the veins of the lower limb: extensions, refinements, and clinical application. J Vasc Surg 41:719-724, 2005

4. Chan AT, Atiemo A, Diran LK, Licholai GP, McLaren Black P, Creager MA, et al: Venous thromboembolism occurs frequently in patients undergoing brain tumor surgery despite prophylaxis. J Thromb Thrombolysis 8:139-142, 1999

5. Coen Herak D, Milos M, Zadro R: Evaluation of the Innovance D-DIMER analytical performance. Clin Chem Lab Med 47: 945-951, 2009

6. Cohen AT, Agnelli G, Anderson FA, Arcelus JI, Bergqvist D, Brecht JG, et al: Venous thromboembolism (VTE) in Europe. The number of VTE events and associated morbidity and mortality. Thromb Haemost 98:756-764, 2007

7. Danish SF, Burnett MG, Stein SC: Prophylaxis for deep venous thrombosis in patients with craniotomies: a review. Neurosurg Focus 17(4):E2, 2004

8. de Moerloose P, Palareti G, Aguilar C, Legnani C, Reber G, Peetz D: A multicenter evaluation of a new quantitative highly sensitive D-dimer assay for exclusion of venous thromboembolism. Thromb Haemost 100:505-512, 2008

9. Dermody M, Alessi-Chinetti J, Iafrati MD, Estes JM: The utility of screening for deep venous thrombosis in asymptomatic, non-ambulatory neurosurgical patients. J Vasc Surg 53:13091315,2011

10. Dindo D, Breitenstein S, Hahnloser D, Seifert B, Yakarisik S, Asmis LM, et al: Kinetics of D-dimer after general surgery. Blood Coagul Fibrinolysis 20:347-352, 2009

11. Galanaud JP, Quenet S, Rivron-Guillot K, Quere I, Sanchez Muñoz-Torrero JF, Tolosa C, et al: Comparison of the clinical history of symptomatic isolated distal deep-vein thrombosis vs. proximal deep vein thrombosis in 11,086 patients. J Thromb Haemost 7:2028-2034, 2009

12. Gillet JL, Perrin MR, Allaert FA: Short-term and mid-term outcome of isolated symptomatic muscular calf vein thrombosis. J Vasc Surg 46:513-519, 2007

13. Hamilton MG, Hull RD, Pineo GF: Venous thromboembolism in neurosurgery and neurology patients: a review. Neurosurgery 34:280-296, 1994

14. Heesen M, Kemkes-Matthes B, Deinsberger W, Boldt J, Mat- thes KJ: Coagulation alterations in patients undergoing elective craniotomy. Surg Neurol 47:35-38, 1997

15. Kawaguchi T, Kumabe T, Kanamori M, Nakamura T, Saito R, Yamashita Y, et al: Early detection of venous thromboembolism in patients with neuroepithelial tumor: efficacy of screening with serum D-dimer measurements and Doppler ultrasonography. J Neurooncol 101:495-504, 2011

16. Kearon C: Natural history of venous thromboembolism. Circulation 107 (23 Suppl 1):I22-I30, 2003

17. Khaldi A, Helo N, Schneck MJ, Origitano TC: Venous thromboembolism: deep venous thrombosis and pulmonary embolism in a neurosurgical population. Clinical article. J Neurosurg 114:40-46, 2011

18. Knowlson L, Bacchu S, Paneesha S, McManus A, Randall K, Rose P: Elevated D-dimers are also a marker of underlying malignancy and increased mortality in the absence of venous thromboembolism. J Clin Pathol 63:818-822, 2010

19. Lippi G, Veraldi GF, Fraccaroli M, Manzato F, Cordiano C, Guidi G: Variation of plasma D-dimer following surgery: implications for prediction of postoperative venous thromboembolism. Clin Exp Med 1:161-164, 2001

20. Masuda EM, Kistner RL: The case for managing calf vein thrombi with duplex surveillance and selective anticoagulation. Dis Mon 56:601-613, 2010

21. Palareti G, Cosmi B, Lessiani G, Rodorigo G, Guazzaloca G, Brusi C, et al: Evolution of untreated calf deep-vein thrombosis in high risk symptomatic outpatients: the blind, prospective CALTHRO study. Thromb Haemost 104:1063-1070, 2010

22. Raimondi P, Bongard O, de Moerloose P, Reber G, Waldvogel F, Bounameaux H: D-dimer plasma concentration in various clinical conditions: implication for the use of this test in the diagnostic approach of venous thromboembolism. Thromb Res 69:125-130, 1993

23. Righini M, Paris S, Le Gal G, Laroche JP, Perrier A, Bounameaux H: Clinical relevance of distal deep vein thrombosis. Review of literature data. Thromb Haemost 95:56-64, 2006

24. Stein PD, Matta F, Musani MH, Diaczok B: Silent pulmonary embolism in patients with deep venous thrombosis: a systematic review. Am J Med 123:426-431, 2010

25. Taylor FB Jr, Toh CH, Hoots WK, Wada H, Levi M: Towards definition, clinical and laboratory criteria, and a scoring system for disseminated intravascular coagulation. Thromb Haemost 86:1327-1330, 2001

26. Ten Cate-Hoek AJ, Prins MH: Management studies using a combination of D-dimer test result and clinical probability to rule out venous thromboembolism: a systematic review. J Thromb Haemost 3:2465-2470, 2005

27. Vaitkus PT, Leizorovicz A, Cohen AT, Turpie AG, Olsson CG, Goldhaber SZ: Mortality rates and risk factors for asymptomatic deep vein thrombosis in medical patients. Thromb Haemost 93:76-79, 2005

28. Wells PS: The role of qualitative D-dimer assays, clinical probability, and noninvasive imaging tests for the diagnosis of deep vein thrombosis and pulmonary embolism. Semin Vasc Med 5:340-350, 2005

29. White RH, Zhou H, Romano PS: Incidence of symptomatic venous thromboembolism after different elective or urgent surgical procedures. Thromb Haemost 90:446-455, 2003

30. Youden WJ: Index for rating diagnostic tests. Cancer 3:32-35, 1950

Manuscript submitted January 22, 2013.

Accepted May 23, 2013.

Please include this information when citing this paper: published online August 6, 2013; DOI: 10.3171/2013.5.JNS13151.

Address correspondence to: Julian Prell, M.D., Department of Neurosurgery, University of Halle, Ernst-Grube-Str. 40, Halle 06097, Germany. email: julian.prell@medizin.uni-halle.de. 